\title{
Evaluation of Gamma Penetration through Plain Carbon Steels
}

\author{
H. Durmaz, A. Beril Tugrul and B. BuyuK* \\ Istanbul Technical University, Energy Institute, Nuclear Researches Division \\ ITU Ayazaga Campus, 34469, Sariyer, Istanbul, Turkey
}

\begin{abstract}
In this study, 1010, 1040, 1050 and 1090 carbonized steels were investigated against gamma radioisotope sources on their gamma attenuation properties. Co-60, Cs-137 and Ir-192 gamma radioisotopes which are commonly used in industrial applications were used in the experiments. Half-value layers were carried out for studied carbonized steels against all studied gamma radioisotopes. In addition, the linear and mass attenuation coefficients were determined for each carbonized steels at different gamma radioisotope sources. The theoretical mass attenuation coefficients were calculated from XCOM computer code for all samples at specific energies of Co-60, Cs-137 and Ir-192 gamma sources. The theoretical and experimental results were compared with each other.
\end{abstract}

DOI: 10.12693 /APhysPolA.125.469

PACS: 25.20.Dc

\section{Introduction}

Plain-carbon steel is the most known form of steel, because it provides material properties that are acceptable for many applications. Low carbon steel contains approximately $0.05-0.15 \%$ carbon and mild steel contains $0.16-$ $0.29 \%$ carbon, making it malleable and ductile [1]. The density of plain-carbon steel is approximately $7.85 \mathrm{~g} / \mathrm{cm}^{3}$ and the Young modulus is $210 \mathrm{GPa}[2,3]$.

Radiation shielding is based on the principle of attenuation, which is the ability to reduce a wave's or ray's effect by blocking or bouncing particles through a barrier material. Charged particles may be attenuated by losing energy to reactions with electrons in the barrier, while X-ray and gamma radiation are attenuated through photoemission, scattering, or pair production. Therefore, shielding is important during the radiation working. It is necessity closing to the radiation source door working period when studying with radiation. It is caused by the using of shield for taking the doses at the permissible levels. Steels are used frequently in radiation shielding systems.

Usually carbonized steels which include 1010, 1040, 1050 , and 1090 steels are preferred in radiation shielding equipments. In this study, 1010, 1040, 1050 and 1090 carbonized steels were investigated against gamma radioisotope sources on their gamma attenuation properties.

\section{Experimental procedure}

Four different plain-carbon steel specimens, with the alloy ratios shown in Table I were prepared in plate form at different thicknesses with $0.5,1.0$, and $2.5 \mathrm{~cm}$ [4]. The samples, which were produced by experts, were 1010, 1040, 1050, and 1090 according to SAE-AISI system.

For the experiments, three different gamma radioisotope sources were used for the experiments which are

\footnotetext{
*corresponding author; e-mail: buyukbu@itu.edu.tr
}

Composition of the plain-carbon steels.

TABLE I

\begin{tabular}{|c|c|c|c|c|c|}
\hline \multicolumn{2}{|c|}{ Norm Systems } & \multicolumn{2}{|c|}{ Chemical alloy ratios } & \multirow{2}{*}{$\mathrm{P}_{\max }$} & \multirow[t]{2}{*}{$\mathrm{S}_{\max }$} \\
\hline UNS & -AISI & $\mathrm{C}$ & $\mathrm{Mn}$ & & \\
\hline G10100 & 1010 & $0.08-0.13$ & $0.30-0.60$ & 0.040 & 0.050 \\
\hline G10400 & 1040 & $0.37-0.44$ & $0.60-0.90$ & 0.040 & 0.050 \\
\hline G10500 & 1050 & $0.48-0.55$ & $0.60-0.90$ & 0.040 & 0.050 \\
\hline G10900 & 1090 & $0.85-0.98$ & $0.60-0.90$ & 0.040 & 0.050 \\
\hline
\end{tabular}

commonly used in industrial applications. One of them was Cs-137 that has monochromatic gamma source, the second one was Co-60 that has bichromatic gamma source and last one is Ir-192 that is multichromatic source with nighteen gamma peaks. The properties of working gamma source were shown in Table II.

TABLE II

Properties of gamma sources.

\begin{tabular}{|c|c|c|}
\hline Isotope (half-life) & Energy [keV] (abundance [\%]) & Activity \\
\hline Co-60 (5.26 y) & $1173(100) ; 1332(100)$ & $0.04 \mathrm{mCi}$ \\
\hline Cs-137(30.00 y) & $\begin{array}{lll}667(85) ; & 200(0.5) ; & 210(4.1) ; \\
280(0.4) & \end{array}$ & $11.14 \mu \mathrm{Ci}$ \\
\hline $\operatorname{Ir}-192(74.20 \mathrm{~d})$ & 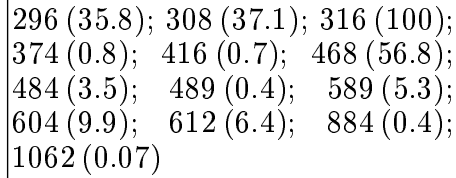 & 0.00 \\
\hline
\end{tabular}

The gamma transmission technique $[5,6]$ and gamma absorption technique [7] are used for materials evaluation for determination of materials attenuation properties against gamma radiation. The gamma transmission technique was used in the evaluation of gamma attenuation in the plain-carbon steels. The technique based on penetrating and transmitting the samples [4]. A T-shaped cylindrical lead collimator was used to provide a parallel beam and to eliminate the surrounding scattering. The source was housed on the same axis with 
collimator and the steel specimens were placed against the gamma source and also collimator hole. A 2 inch diameter $\mathrm{NaI}(\mathrm{Tl})$ scintillation detector, which has high detection efficiency, was used for measuring the gamma spectra. The electronics consisted of a high-voltage supply and multi-channel analyzer system. The experimental setup can be seen in Fig. 1.

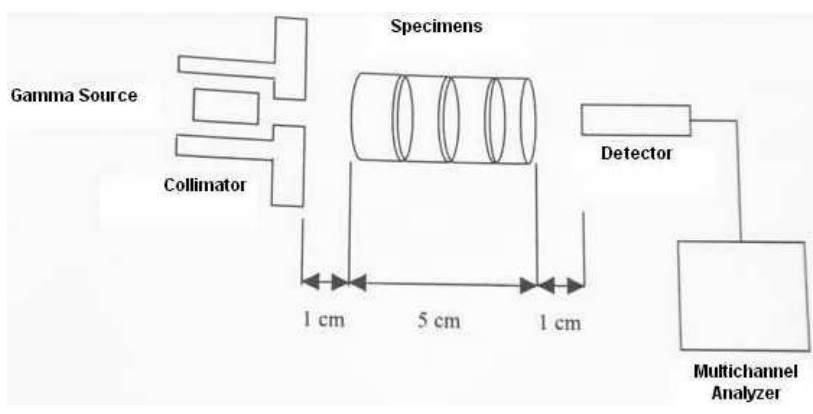

Fig. 1. Experimental setup.

The experimental geometry is important for the reliability of the technique [8]. Therefore, narrow-beam geometry was used during the experiments. The count rates were measured in the same geometry for all samples, and the net counting rates were determined subtracting the background counts from the measured counts. Each data set was recorded during a counting time of $600 \mathrm{~s}$. Experiments were repeated at least three times and the average net count rates were calculated for each analysis.

Theoretical attenuation was calculated using the following equation:

$$
\frac{I}{I_{0}}=\sum_{i=1}^{N} f_{i} \exp \left(\sum_{j=1}^{p}-g \mu_{j} x\right) .
$$

$f_{i}$ represents of abundance of $i$-th energy peak of the gamma source, $g$ is the alloy ratio, $\mu_{j}$ is the $j$-th alloy element, $N$ is the peak number, $p$ is the alloy elements number, and $x$ is the thickness of the sample [9]. In addition of it, XCOM computer code [10] also was used for calculation for the mass attenuation coefficients. Additionally, the half value layer (HVL) was calculated as follows ( $\mu$ is the mass attenuation coefficient):

$$
\mathrm{HVL}=0.693 / \mu \text {. }
$$

\section{Experimental results}

Results for plain-carbon steels as 1010, 1040, 1050, and 1090 are given in Table III. Figure 2 shows the results of the attenuation through the 1010, 1040, 1050, and 1090 steels for different gamma sources, respectively, by using the value of Table II. Figures 3 and 4 show the results for the steel specimen.

The results for half value layers can be seen in Table IV comparatively by using experimental and theoretical linear attenuation coefficients. Average and absolute erors were also given in Table $\mathrm{V}$.
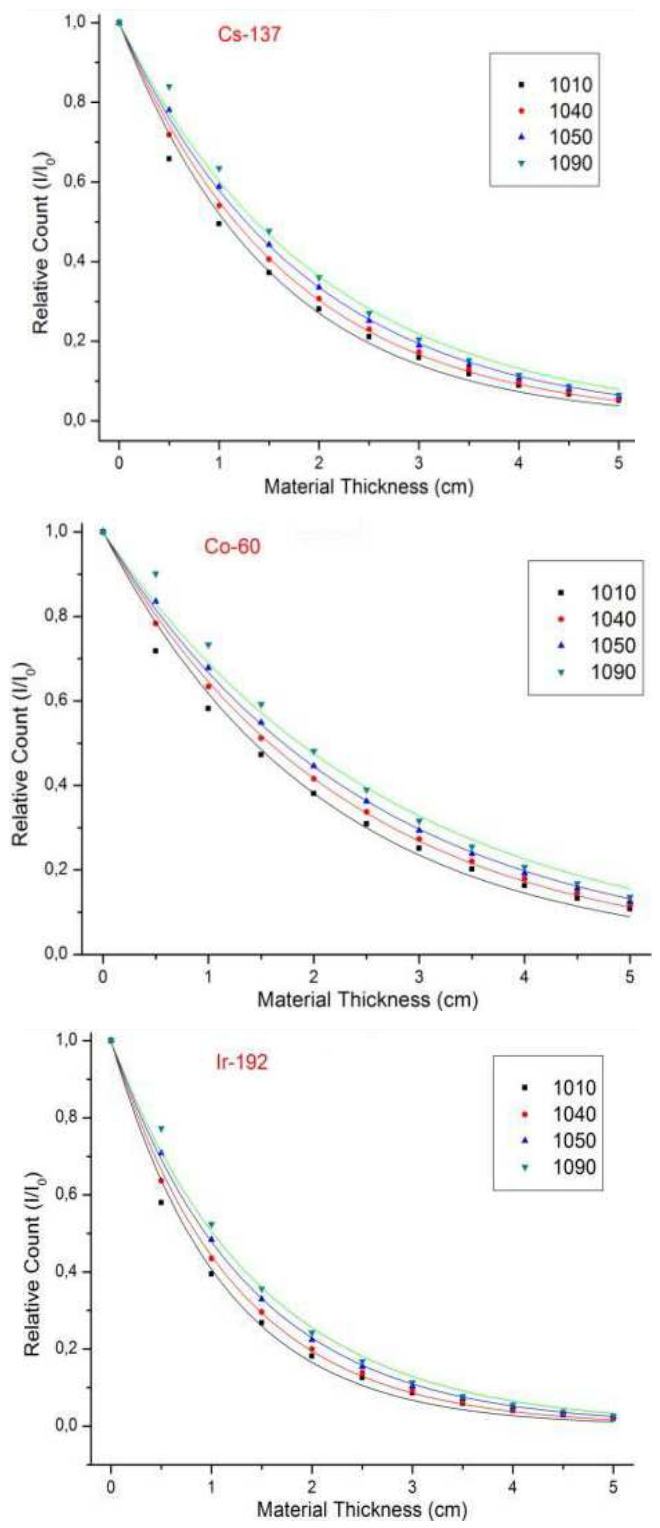

Fig. 2. Results with Cs-137, Co-60, and Ir-192 sources.

From Table II the linear attenuation coefficient of the samples were calculated by using origin program. Linear attenuation coefficients of 1010, 1040, 1050, and 1090 plain carbon steels were listed in Table IV.

TABLE IV

Linear attenuation coefficients of 1010, 1040, 1050, and 1090 plain carbon steels against Cs-137, Co-60 and Ir-192 gamma radiation sources.

\begin{tabular}{c|c|c|c|c|c|c}
\hline \hline \multirow{2}{*}{$\begin{array}{c}\text { Steel } \\
\text { type }\end{array}$} & \multicolumn{5}{|c}{ Linear attenuation coefficient $\left[\mathrm{cm}^{-1}\right]$} \\
\cline { 2 - 7 } & Cs-137 & $\begin{array}{c}\text { Standard } \\
\text { deviation }\end{array}$ & Co-60 & $\begin{array}{c}\text { Standard } \\
\text { deviation }\end{array}$ & Ir-192 & $\begin{array}{c}\text { Std. } \\
\text { deviation }\end{array}$ \\
\hline 1010 & 0.482 & 0.014 & 0.654 & 0.019 & 0.899 & 0.028 \\
1040 & 0.438 & 0.004 & 0.597 & 0.006 & 0.818 & 0.011 \\
1050 & 0.405 & 0.003 & 0.547 & 0.005 & 0.737 & 0.006 \\
1090 & 0.372 & 0.011 & 0.507 & 0.014 & 0.683 & 0.018
\end{tabular}


TABLE III

Experimental results for 1010, 1040, 1050, and 1090 plain carbon steels.

\begin{tabular}{c|c|c|c|c|c|c|c|c|c|c|c|c}
\hline \hline \multirow{2}{*}{$\begin{array}{c}\text { thickness } \\
{[\mathrm{cm}]}\end{array}$} & \multicolumn{10}{c}{ relative counts $\left(I / I_{0}\right)$} \\
\cline { 2 - 13 } & \multicolumn{3}{|c|}{1010} & \multicolumn{3}{c|}{1040} & \multicolumn{3}{c|}{1050} & \multicolumn{3}{c}{1090} \\
\cline { 2 - 12 } & $\mathrm{Co}^{60}$ & $\mathrm{Cs}^{137}$ & $\mathrm{Ir}^{192}$ & $\mathrm{Co}^{60}$ & $\mathrm{Cs}^{137}$ & $\mathrm{Ir}^{192}$ & $\mathrm{Co}^{60}$ & $\mathrm{Cs}^{137}$ & $\mathrm{Ir}^{192}$ & $\mathrm{Co}^{60}$ & $\mathrm{Cs}^{137}$ & $\mathrm{Ir}^{192}$ \\
\hline 0.5 & 0.718 & 0.658 & 0.580 & 0.783 & 0.719 & 0.637 & 0.835 & 0.781 & 0.708 & 0.901 & 0.840 & 0.772 \\
1.0 & 0.582 & 0.495 & 0.395 & 0.634 & 0.541 & 0.435 & 0.678 & 0.588 & 0.484 & 0.733 & 0.634 & 0.524 \\
1.5 & 0.473 & 0.372 & 0.268 & 0.512 & 0.406 & 0.296 & 0.549 & 0.443 & 0.329 & 0.592 & 0.477 & 0.356 \\
2.0 & 0.381 & 0.281 & 0.182 & 0.416 & 0.307 & 0.200 & 0.446 & 0.335 & 0.224 & 0.481 & 0.360 & 0.242 \\
2.5 & 0.309 & 0.211 & 0.126 & 0.337 & 0.230 & 0.139 & 0.362 & 0.251 & 0.155 & 0.390 & 0.270 & 0.168 \\
3.0 & 0.251 & 0.159 & 0.086 & 0.273 & 0.173 & 0.094 & 0.293 & 0.189 & 0.104 & 0.316 & 0.204 & 0.113 \\
3.5 & 0.202 & 0.118 & 0.059 & 0.220 & 0.129 & 0.064 & 0.238 & 0.141 & 0.072 & 0.255 & 0.152 & 0.077 \\
4.0 & 0.163 & 0.089 & 0.041 & 0.179 & 0.097 & 0.046 & 0.192 & 0.107 & 0.050 & 0.207 & 0.115 & 0.055 \\
4.5 & 0.133 & 0.067 & 0.029 & 0.146 & 0.073 & 0.032 & 0.157 & 0.081 & 0.034 & 0.168 & 0.087 & 0.037 \\
5.0 & 0.108 & 0.051 & 0.020 & 0.118 & 0.055 & 0.022 & 0.126 & 0.061 & 0.024 & 0.136 & 0.065 & 0.026
\end{tabular}

HVL for 1010, 1040, 1050, and 1090 plain carbon steels.

TABLE V

\begin{tabular}{|c|c|c|c|c|c|c|c|c|c|}
\hline \multirow{3}{*}{$\begin{array}{l}\text { Steel } \\
\text { type }\end{array}$} & \multicolumn{9}{|c|}{ Half value layer $(\mathrm{HVL})[\mathrm{cm}]$} \\
\hline & \multicolumn{3}{|c|}{ Cs-137 } & \multicolumn{3}{|c|}{ Co-60 } & \multicolumn{3}{|c|}{ Ir-192 } \\
\hline & Exp. & Theor. & Rel. error & Exp. & Theor. & Rel. error & Exp. & Theor. & Rel. error \\
\hline 1010 & 0.985 & 1.145 & -14 & 1.367 & 1.609 & -15 & 0.715 & 0.822 & -13 \\
\hline 1040 & 1.152 & 1.196 & -4 & 1.563 & 1.645 & -5 & 0.84 & 0.866 & -3 \\
\hline 1050 & 1.303 & 1.218 & +7 & 1.738 & 1.704 & 2 & 0.955 & 0.873 & 9 \\
\hline 1090 & 1.427 & 1.274 & +12 & 1.873 & 1.767 & 6 & 1.031 & 0.892 & 16 \\
\hline \multicolumn{3}{|c|}{ Average absolute error [\%] } & $\begin{array}{l}9.25 \\
0.25\end{array}$ & & & $\begin{array}{r}7 \\
-3\end{array}$ & & & $\begin{array}{r}10.25 \\
2.25\end{array}$ \\
\hline
\end{tabular}

\section{Discussion and conclusion}

The curves obtained from the experiments with the plain-carbon steels as 1010, 1040, 1050, and 1090 alloys, for Co-60, Cs-137 and Ir-192 gamma sources in Fig. 2 are appropriate perfectly to each other. The same appropriation was also obtained for four different plain-carbon steels in Figs. 3 and 4. The curves of the low-carbon steels are at the uppermost side, inversely the proportionally high-carbon steels are at the bottom. In addition, the curves within themselves are lined up from low-carbon steel to high-carbon steel in the same array as the calculated mass attenuation coefficients. These results are good and conform to the expectations. Thus, if the carbon value is low then the count rate goes up; therefore, the curves of those samples are in upper positions in the graphs. Inversely, when the carbon value is high, the count rate falls and the curves lie lower in the graph. Table III compares the experimental and theoretical half-value layers which were calculated experimental and theoretical linear attenuation coefficients for four plain-carbon steels. The results appear to be satisfactory and the error values are between 7 and $10.25 \%$. The errors came from the impurity in the specimens. Therefore, it can be said that the calculated results also agree with the experimental results.
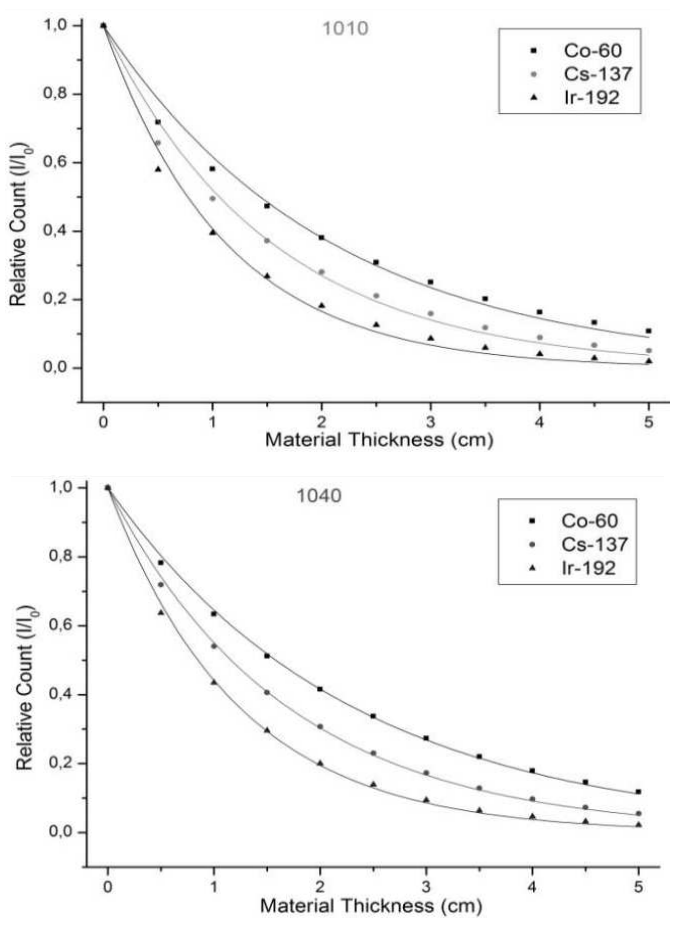

Fig. 3. Results for 1010 and 1040 steel. 

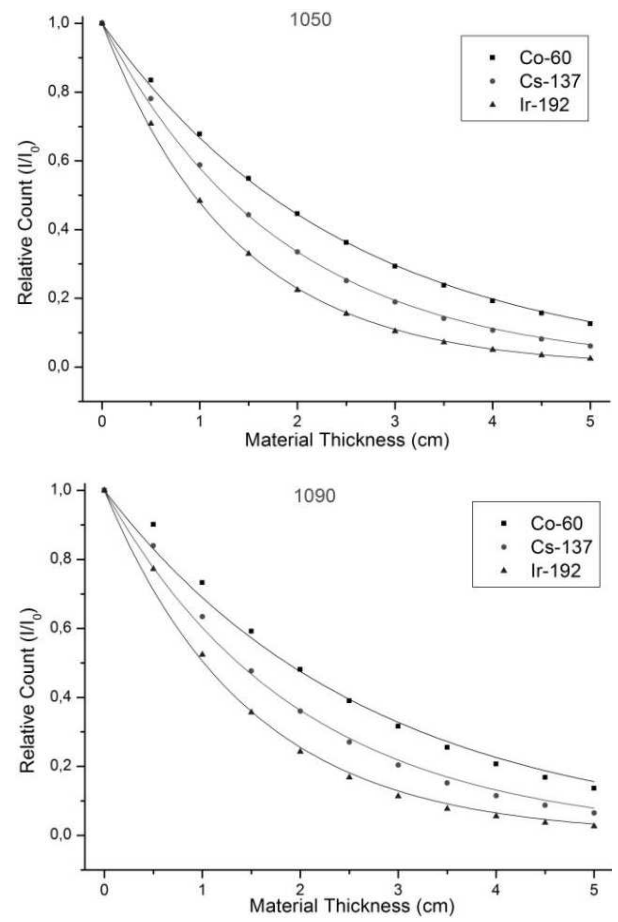

Fig. 4. Results for 1050 and 1090 steel.

\section{References}

[1] Classification of Carbon and Low-Alloy Steels, CM Key to Metals, 2012.

[2] G. Elert, Density of Steel, 2009.

[3] Modulus of Elasticity, Strength Properties of MetalsIron and Steel, 2009.

[4] H. Durmaz, Evaluation of Plain-Carbon Steels for Radiation Shielding, M.Sc. Thesis, Istanbul Technical University, Nuclear Energy Institute, Istanbul 2002.

[5] B. Buyuk, A.B. Tugrul, A.C. Akarsu, A.O. Addemir, Acta Phys. Pol. A 121, 135 (2012).

[6] B. Buyuk, A.B. Tugrul, A.C. Akarsu, A.O. Addemir, J. Nano-Electron. Phys. 4, 01010 (2012).

[7] A. Kurtoğlu, A.B. Tuğrul, Appl. Radiat. Isotop. 58, 5 (2003).

[8] A.B. Tuğrul, Kerntechn. 60, 265 (1995).

[9] R.C. McMaster, Nondestructive Testing Handbook, The Ronald Press Co., New York 1963.

[10] L. Gerward, N. Guilbert, K.B. Jensen, H. Levring, Radiat. Phys. Chem. 60, 23 (2001). 